Revista Perspectivas Online: Exatas \& Engenharias Anais do V Seminário P\&D PROVIC/PIBIC

II Encontro de Iniciação Científica CNPq Vol. 10, $\mathrm{n}^{\mathbf{0}}$ 29, Suplemento, 2020

\title{
Projeto de estação carregadora para alimentar pequenas necessidades elétricas a partir de energia solar
}

\author{
$\underline{\text { Allana Cardoso }}{ }^{1}$ Felipe Silva ${ }^{2}$, Jeferson Silva ${ }^{3}$, André Souza ${ }^{4}$ \\ 1) Aluna Voluntária de Iniciação Científica do PROVIC/ISECENSA - Curso de Engenharia Civil, (2) Aluno Voluntário de Iniciação Científica do \\ PROVIC/ISECENSA - Curso de Engenharia de Produção; (3) Aluno Voluntário de Iniciação Científica do PROVIC/ISECENSA - Curso de \\ Engenharia Mecânica, (4) Pesquisador Orientador - Curso de Engenharia de Produção - ISECENSA, Institutos Superiores de Ensino do CENSA - \\ ISECENSA, Rua Salvador Correa, 139, Centro, Campos dos Goytacazes, RJ, Brasil.
}

A utilização dos combustíveis fósseis para a geração de energia está atrelada a uma série de problemas, que vão desde os impactos ambientais causados até a insuficiência para suprir a demanda de consumo mundial. Neste contexto, muitas pesquisas relacionadas a fontes alternativas e renováveis de energia vêm sendo realizadas, tornando estas tecnologias cada vez mais viáveis. A Energia Solar Fotovoltaica, apesar dos desafios e limitações associadas à sua aplicação, apresenta-se como uma das melhores alternativas para suprir parte da demanda e também viabilizar o acesso à energia elétrica em regiões necessitadas, através de pequenas estações. Essa modalidade ganha força em países como o Brasil, onde existe grande abundância de recursos solares. O presente trabalho teve como objetivo elaborar o projeto de uma estrutura de mobiliário urbano dotada de módulos fotovoltaicos para o abastecimento de pequenas necessidades energéticas. A metodologia teve início na definição do local para a instalação da estação e realização de medições em visitas técnicas. Em seguida, foram compilados os dados solarimétricos para o local, interpolando os resultados para as bases de dados SunData e RADIASOL 2, e definindo a inclinação e orientação dos módulos. A demanda energética da estação foi determinada a partir do consumo de cada equipamento que seria instalado, para, posteriormente, dimensionar o gerador e o banco de baterias, baseados no método do mês crítico para sistemas off-grid. A partir do gerador e do banco de baterias, foram dimensionados e selecionados o controlador de carga e o inversor adequados para o sistema. O resultado da escolha do local forneceu as coordenadas $21,76^{\circ} \mathrm{S}$ e $41,33^{\circ} \mathrm{W}$, e mostrou ter área suficiente e livre de sombreamento. A carga determinada a partir dos dispositivos que seriam utilizados foi de $67,4 \mathrm{kWh} / \mathrm{mês}$. Os dados solarimétricos forneceram um ângulo de inclinação de $27^{\circ}$ e orientação norte como as melhores opções para o posicionamento dos módulos. O modelo escolhido de módulo fotovoltaico foi o Upsolar UP-M155P, devido à sua boa razão custo x benefício, e o dimensionamento informou que seriam necessários 5 módulos para o abastecimento da energia necessária, ocupando uma área com cerca de $5 \mathrm{~m}^{2}$. A bateria escolhida foi do modelo Heliar Freedom DF4100, e foi calculado que seriam necessárias 4 baterias para uma profundidade de descarga de $20 \%$. A partir do arranjo escolhido, foram especificados o controlador Epever Tracer 6415AN e o inversor Epever IPower IP350-11. Os resultados obtidos permitem concluir que o dimensionamento foi realizado de forma satisfatória para abastecer às necessidades. A pequena área ocupada pelo sistema, com $5 \mathrm{~m}^{2} \mathrm{de}$ módulos, se mostrou um fator positivo, tendo em vista que é facilmente adaptável a 
Revista Perspectivas Online: Exatas \& Engenharias Anais do V Seminário P\&D PROVIC/PIBIC

II Encontro de Iniciação Científica CNPq Vol. 10, n 29 , Suplemento, 2020

outras localidades e aplicações. O custo principal do sistema ficou por conta das baterias, representando $46 \%$ do custo do gerador solar.

Palavras-chave: Energia renovável; Energia solar fotovoltaica; Estação de carregamento.

Instituição de Fomento: ISECENSA. 